\title{
Cuidados com o corpo entre alunos do ensino básico: uma revisão integrativa
}

\author{
Body care among elementary students: an integrative review \\ Cuidado con el cuerpo entre estudiantes de educación básica: una revisión integradora \\ Rosângela Lima da Silva ${ }^{1 *}$, Edna Ferreira Coelho Galvão'.
}

\section{RESUMO}

Objetivo: Realizar uma revisão integrativa da literatura para identificar os cuidados corporais mais relevantes entre alunos do ensino básico e quais fatores estão associados a estes cuidados. Métodos: Os bancos de dados utilizados: Biblioteca virtual em saúde do adolescente (Adolec) $(n=159)$; National Library of Medicine (Pubmed) ( $n=2)$; Biblioteca Virtual em saúde (BVSaúde) ( $n=9)$; Scientific Electronic Library Online (Scielo) $(n=46)$ e Google Acadêmico $(n=34)$. Os artigos selecionados faziam abordagem aos cuidados com a saúde entre escolares de 5 a 18 anos a partir da percepção que os mesmos tinham de seu corpo. Foram utilizados apenas artigos originais e com realização no Brasil. No total, foram encontrados 250 artigos, destes, 241 foram excluídos pelo título, 27 excluído pelo resumo e 1 excluído pela duplicidade, ficando apenas 3 para fazer parte desta revisão. Resultados: Percebemos que os estudos evidenciaram que os escolares estão insatisfeitos com seus corpos e que os mesmos não têm cuidados corporais indicados. Nos estudos foi exposto que tal insatisfação pode afetar diretamente na saúde e bem-estar. Considerações finais: Percebese ações em saúde no ambiente escolar, caso fossem desenvolvidas, poderiam permitir aos escolares acesso aos conhecimentos sobre como cuidar do seu corpo e por fim, ter uma saúde melhor.

Palavras-chaves: Autocuidado, Estudantes, Saúde.

\begin{abstract}
Objective: Conduct an integrative literature review to identify the most relevant body care among elementary school students and what factors are associated with this care. Methods: The databases used: Virtual library on adolescent health (Adolec) $(n=159)$; National Library of Medicine (Pubmed) $(n=2)$; Virtual Health Library (BVSaúde) $(n=9)$; Scientific Electronic Library Online (Scielo) $(n=46)$ and Google Scholar $(n=34)$. The selected articles approached health care among schoolchildren aged 5 to 18 years based on their perception of their body. Only original articles used in Brazil were used. In total, 250 articles were found, of these, 241 were excluded by the title, 27 excluded by the abstract and 1 excluded by duplication, leaving only 3 to be part of this review. Results: We realized that the studies showed that the students are dissatisfied with their bodies and that they do not have indicated body care. Studies have shown that such dissatisfaction can directly affect health and well-being. Final considerations: perceived health actions in the school environment, if developed, could allow students to access knowledge about how to take care of their bodies and, finally, have better health.
\end{abstract}

Keywords: Self-care, Students, Health.

\section{RESUMEN}

Objetivo: realizar una revisión de literatura integradora para identificar el cuidado corporal más relevante entre los estudiantes de primaria y qué factores están asociados con este cuidado. Métodos: Las bases de datos utilizadas: Biblioteca virtual sobre salud adolescente (Adolec) $(n=159)$; Biblioteca Nacional de Medicina (Pubmed) ( $n=2)$; Biblioteca Virtual en Salud (BVSaúde) $(n=9)$; Biblioteca electrónica científica en línea (Scielo) $(n=46)$ y Google Scholar $(n=34)$. Los artículos seleccionados abordaron la atención de la salud entre los escolares de 5 a 18 años en función de su percepción de su cuerpo. Solo se usaron artículos originales utilizados en Brasil. En total, se encontraron 250 artículos, de estos, 241 fueron excluidos por el

${ }_{1}^{1}$ Programa de Pós-graduação Ensino em Saúde na Amazônia - Universidade do Estado do Pará (UEPA), Belém-Pará. *E-mail: hmrose@gmail.com

SUBMETIDO EM: 11/2019 
título, 27 excluidos por el resumen y 1 excluido por duplicación, dejando solo 3 para ser parte de esta revisión. Resultados: Nos dimos cuenta de que los estudios mostraron que los estudiantes están insatisfechos con sus cuerpos y que no tienen cuidado corporal indicado. Los estudios han demostrado que tal insatisfacción puede afectar directamente la salud y el bienestar. Consideraciones finales: las acciones de salud percibidas en el entorno escolar, si se desarrollan, podrían permitir a los estudiantes acceder a conocimientos sobre cómo cuidar sus cuerpos y, finalmente, tener una mejor salud.

Palabras clave: Autocuidado, Estudiantes, Salud.

\section{INTRODUÇÃO}

Os cuidados com o corpo devem ser considerados desde o nascimento, visto que, um corpo bem cuidado é considerado um corpo saudável (FICAGNA JB, 2014). Entre os vários cuidados com o corpo, enfatizamos aqui a higiene pessoal, uma boa alimentação, prática de atividade física, os cuidados com o meio ambiente e a interrelação com outras pessoas, que quando praticados rotineiramente melhoram a saúde, o bem-estar e a qualidade de vida (SILVA A, et al., 2015).

Em relação aos cuidados corporais, é imprescindível que cada indivíduo cuide de si para que possa ter uma boa saúde, e nesse sentido, ressaltamos a higiene pessoal que nos ajudam na prevenção de doenças, mantendo o corpo limpo e forte. Hábitos diários, como tomar banho, escovar os dentes, lavar as mãos, cortar as unhas e até mesmo lavar os cabelos, nos possibilita uma sensação de bem-estar. Fazer isso melhora, inclusive, nossa relação pessoal com outras pessoas, seja no seio familiar, no trabalho ou com nossos amigos (FONSECA E, et al., 2015). Não podemos também esquecer de ressaltar sobre alimentação saudável, pois quando nos habituamos em consumir alimentos de forma e horários corretos, evitando excessos, passamos à sentir verdadeiras mudanças, sejam na estrutura corporal como também nas sensações como respiração mais compassada, batimentos cardíacos controlados e um melhor funcionamento do nosso organismo. Assim, recomenda-se evitar o excesso de gorduras, sal e açúcar e uma melhor distribuição quanto ao consumo de verduras, legumes e frutas (KRAEMER FB, et al., 2014).

Relacionado às práticas de atividade física, a Organização Mundial da Saúde (OMS), fala sobre a média de tempo que devemos nos exercitar semanalmente, contabilizando 150 minutos. Sabe-se que a atividade física pode trazer diversos benefícios tanto para o corpo, como para a mente, e entre os benefícios podemos citar a manutenção do percentual de gordura, fortalecimentos articulares, ósseo e musculares, além, é claro, da diminuição da incidência de doenças como hipertensão, acidentes vasculares, ansiedade e até mesmo a depressão (BRASIL, 2017).

Assim, ainda nos remontamos a falar do meio ambiente, o lugar que vivemos que tem estrita relação com os cuidados corporais, pois devemos manter limpo o lugar que vivemos. Cuidar da limpeza de nossas casas, da rua que moramos, das praças, praias e demais lugares que costumamos frequentar, também é questão de cuidado. E não vai restringir a cuidar apenas de si, mas também de outras pessoas, quer sejam familiares, amigos ou completos desconhecidos, mas que podem influenciar, também, nas nossas relações interpessoais (ZACARIAS EFJ, HIGUCHI MIG, 2017).

Relacionado à tais cuidados, sabe-se que no seio familiar muitos são os aprendizados que a criança pode adquirir com base na rotina familiar, porém a escola como promotora de aprendizado mútuo, pode influenciar os alunos para que tenham uma maior atenção quando se trata da saúde do seu corpo. Ressaltamos que, documentos como Parâmetro Curricular Nacional (PCN), Base Nacional Comum Curricular (BNCC) e a própria Lei de Diretrizes e Bases (LDB), trazem informações quanto à devida atenção que deve-se ter para com informações relacionadas aos cuidados com o corpo, observando a autonomia que o professor tem em construir aulas em que os alunos sejam autores do seu conhecimento (BRASIL, 1997; BRASIL, 2018; BRASIL, 2017).

$\mathrm{Na}$ escola, por se espaço de constante aprendizado e rica em diversidade, o aluno tem oportunidade de construir e reconstruir seus saberes colocando em prática tudo que foi aprendido, além de trocar experiências com os demais alunos e assim enriquecer seus conhecimentos. E nesse espaço, deveria haver ações educativas que pudessem auxiliar os alunos nos cuidados com seu corpo, prezando pelas particularidades culturais na qual ele está inserido. Tais ações, caso sejam bem planejadas e desenvolvidas, provocam 
benefícios tanto para os alunos, para família e também para escola, pois assim os alunos se tornam mais conscientes no trato com o corpo (DA SILVA MC, BAPTISTA GG, 2014).

Estudos apontam que, ao utilizarmos ações educativas no espaço escolar, temos alunos mais preocupados e conscientes em dar atenção a seu corpo e, por conseguinte à sua saúde (OLIVEIRA FPSL, et al.). Outro fato é que, muitos alunos têm uma imagem de cuidado corporal relacionado à questão estética, e acabam por querer cuidar do corpo para que possam ser bem vistos pelos seus pares. Mas, podemos observar em outro estudo que objetivava perceber se práticas educativas voltadas para o trato com o corpo seriam benéficas, onde nos resultados percebeu-se que ao desenvolver aulas que concebessem a participação dos alunos para uma melhor compreensão do corpo, os alunos apontaram ser de grande valia tais ações, evidenciando a aceitabilidade em práticas que promovam a saúde entre os escolares a partir dos cuidados que tem com seu corpo, fazendo-os também mais críticos quantos aos padrões de beleza existente, e por fim minimizando atitudes desenfreadas que acabam por culminar em atitudes errôneas para alcançar um falso padrão aceitável peal sociedade (FICAGNA JB, 2014).

Diante do exposto, o objetivo desta revisão integrativa foi de identificar os cuidados corporais mais relevantes entre alunos do ensino básico e quais fatores estão associados a este cuidado. Ressalta-se a importância de saber sobre a relação de tais cuidados nos trabalhos publicados com margem a enfatizar a importância de práticas educativas que possibilitem que crianças e adolescentes possam ter conhecimentos sobre seu corpo e de como cuidar dele e de forma significativa, ter uma melhor saúde e esclarecimentos sobre sua imagem corporal.

\section{MÉTODOS}

O presente estudo é fruto de uma pesquisa exploratória com abordagem qualitativa, configurada como uma revisão integrativa. Para construção deste trabalho foi realizada uma pesquisa integrativa em banco de dados que houvesse publicações de artigos entre os anos de 2015 e 2019, nas bases de dados: Biblioteca virtual em saúde do adolescente (Adolec), National Library of Medicine (Pubmed), Biblioteca Virtual em saúde (BVSaúde), Scientific Electronic Library Online (Scielo) e Google Acadêmico. Como suporte, utilizamos o que está recomendado do método Systematic Reviews and Meta-Analyses (PRISMA), que é composto por uma lista de 27 itens e um fluxograma que norteiam os autores a produção de melhores e confiáveis produções de revisões (MOHER D, et al., 2015).

O questionamento principal para construção deste artigo foi: Os escolares têm cuidado do seu corpo? Qual a visão de cuidado com o corpo os escolares têm? Quais as principais formas de cuidados com o corpo têm sido utilizadas pelos escolares? Quais as ações em saúde estão sendo desenvolvidas no espaço escolar?

Foram utilizados Termos Livres (TL) - termos não encontrados no Descritores em Ciências da Saúde (DECs), mas que seriam de grande relevância para a pesquisa; os termos foram: "corporal"; "escolares" e também utilizando um dos DECs "saúde". Os estudos deveriam ser de cunho nacional (Brasil). Para combinar as palavras-chaves, foi inserido o operador "AND" entre as palavras (LIMA ACD, et al., 2018).

Os critérios de inclusão utilizados foram: artigos originais que abordassem os cuidados com a saúde entre escolares e que os trabalhos fossem produzidos no contexto nacional (Brasil). Foram excluídos trabalhos de revisão, livros, capítulos de livros, relato de experiência e os editoriais, dissertações e teses. Pesquisas que não foram realizadas no espaço escolar, também foram excluídas, além daqueles que não tratassem especificamente dos cuidados com a saúde do aluno de ensino básico.

Os trabalhos selecionados, a partir dos TLs e do DECs, foram organizados em etapas descritas a seguir: 1aㅡ etapa: leitura dos títulos encontrados nos bancos de dados, com posterior inclusão e exclusão (seguindo os critérios); $2^{\mathrm{a}}$ etapa: leitura dos resumos para averiguação de quais estudos se enquadrariam na temática abordada; $3^{a}$ etapa: leitura do texto na íntegra afim de fortalecer os itens de inclusão e exclusão para compor este trabalho.

Ainda como parte integrante do processo de seleção dos trabalhos para construir este artigo, todos que fossem repetidos nas diferentes bases de dados, foram excluídos logo após a leitura na íntegra, para evitar possíveis erros de exclusão. Vale ressaltar que todas as etapas foram feitas por dois autores, afim de dar maior confiabilidade e exatidão no que foi pesquisado. 
Os estudos, para que fossem selecionados deveriam ter: Público alvo (alunos do ensino básico), pesquisas realizadas no espaço escolar, pesquisas originais (artigos), pesquisas realizadas no Brasil. Os trabalhos encontrados, oriundos de revisão bibliográfica, foram descartados. Os resultados foram organizados em quadros, evidenciando os autores, título do trabalho, objetivo principal, público alvo, método utilizado e resultados encontrados. Para discussão de dados, nos baseamos em Bardin L (2011, p. 95), que consiste em uma análise de conteúdo com propósito de "apurar descrições de conteúdo muito aproximativas, subjetivas, para pôr em evidência com objetividade a natureza e as forças relativas dos estímulos". Tal técnica nos permite explorar o material, tratar dos resultados, fazendo organizações necessárias e por fim, interpretar os dados coletados (BARDIN L, 2011). Para que pudéssemos ter uma melhor visão dos trabalhos encontrados, excluídos, incluídos para leitura e os selecionados para estudo, organizamos o passo a passo no fluxograma (Figura 1).

Figura 1 - fluxograma com o quantitativo de trabalhos encontrados e selecionados, após aplicação dos critérios estabelecidos.

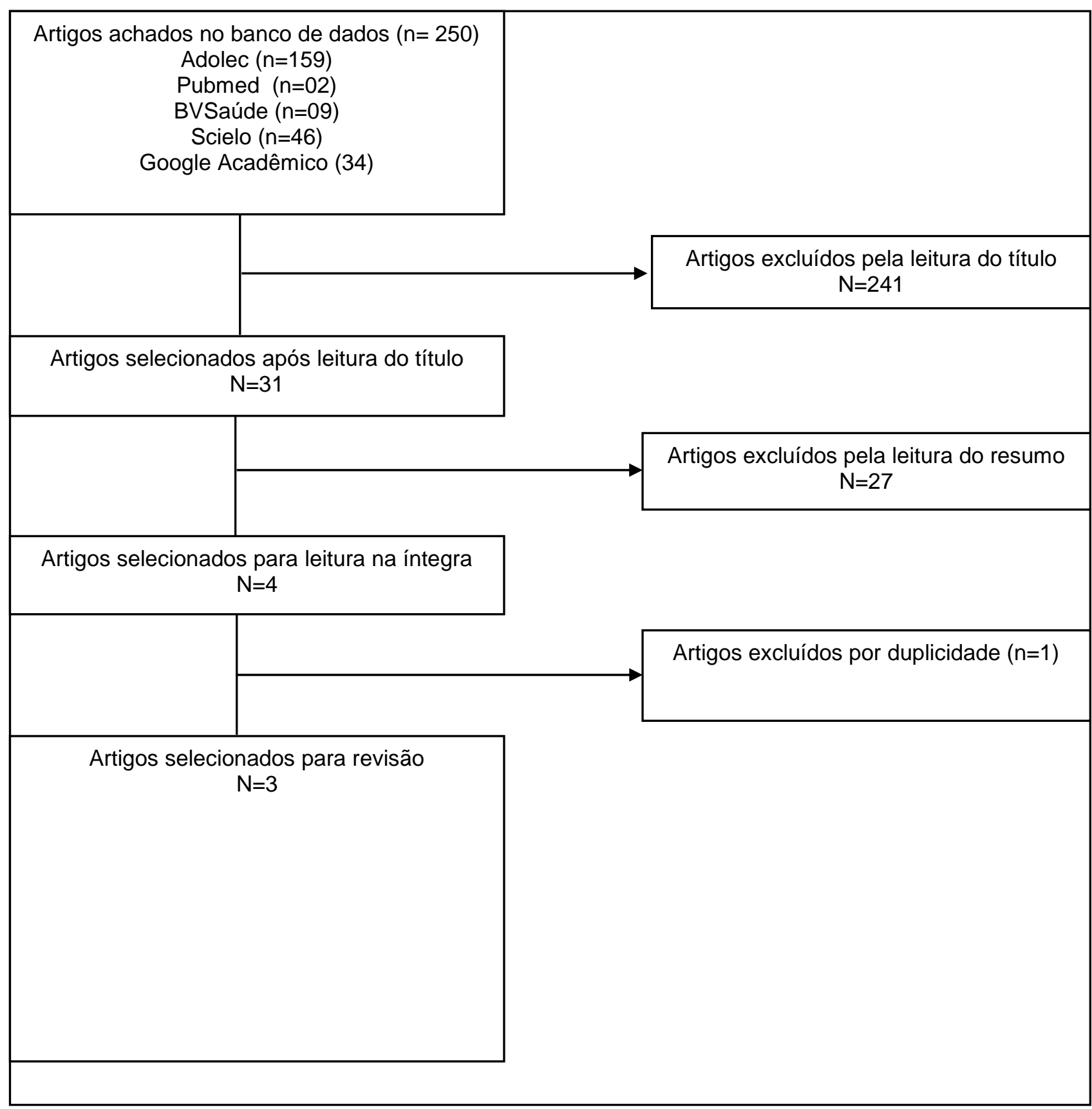

Fonte: Silva RL e Galvão EFC, 2019. 
Como consta na Figura 1, nas buscas feitas conseguimos encontrar 250 artigos, usando o descritor e os TL, sendo 159 no Adolec, 2 no Pubmed, 9 no Bvsaúde, 46 no scielo e 34 no Google Acadêmico. Ao final do processo de seleção, ficamos com 3 artigos, que mais se aproximavam dos questionamentos levantados, para podermos fazer a presente revisão.

\section{RESULTADOS E DISCUSSÃO}

Os artigos analisados estão compreendidos entre os anos de 2015 e 2019 e com realização no Brasil, situados nas regiões sul, Norte e nordeste do Brasil, sendo 1 estudo em cada região. Os estudos estão relacionados sobre questões dos hábitos relacionado aos cuidados que o mesmo tem com sua saúde, variando entre questões de conhecimentos acerca de hábitos alimentares, prática de atividade física e como eles enxergam e cuidam do seu corpo. Os estudos trazem em seus objetivos pontos em comum, pois levam em consideração o que os participantes das pesquisas conhecem sobre os pontos abordados, deixando eles contribuírem com suas falas para escrita dos estudos.

Os públicos alvos tratados nos trabalhos são escolares, e o quantitativo varia entre 76 e 2.694, com idade entre 5 a 18 anos, sendo que 1 estudo foi feito com crianças de 5 a 10 anos e os demais com adolescente de 14 a 18 anos. Podemos observar que estudos com crianças na pré-puberdade não foram achados, porém destaca-se que em qualquer faixa etária, crianças ou adolescentes, podem participar das pesquisas relacionado ao tema saúde, dentro do espaço escolar. Além do que, fazemos uma observação quanto a fase de mudanças corporais que ocorrem na fase da pré-puberdade fazendo com que muitas delas fiquem em dúvidas relacionados às transformações que ocorrem em sua maturação. Segue no Quadro 1, as questões observadas nos artigos selecionados. 
Quadro 1 - Análise do estudo de Farias E, et al., 2019; Lemes DCM, et al., 2018; Pedraza DF, et al., 2018.

\begin{tabular}{|c|c|c|c|c|}
\hline Autores/Ano & Objetivo & Amostra & Metodologia & Resultados \\
\hline $\begin{array}{l}\text { Farias E, et } \\
\text { al., } 2019\end{array}$ & $\begin{array}{l}\text { Identificar a prevalência } \\
\text { do comportamento } \\
\text { inativo de estudantes } \\
\text { adolescentes da cidade } \\
\text { de Porto Velho, RO, } \\
\text { Brasil, e os fatores } \\
\text { associados a ele }\end{array}$ & $\begin{array}{l}2.694 \\
\text { adolescentes } \\
\text { Entre } 14 \text { e } 18 \\
\quad \text { anos } \\
\text { Porto } \\
\text { Velho/RO } \\
\text { Região norte } \\
\text { do Brasil. }\end{array}$ & $\begin{array}{c}\text { Estudo transversal de base escolar. A } \\
\text { prática habitual de atividade física foi } \\
\text { obtida pelo Questionário Internacional } \\
\text { de Atividade Física, versão curta } \\
\text { (Guedes et al.). As respostas para a } \\
\text { questão da percepção de saúde foram } \\
\text { categorizadas em escala de Likert de } 5 \\
\text { opções, de excelente até ruim. Para } \\
\text { análise dos dados, optou-se por } \\
\text { categorizar as respostas em positiva e } \\
\text { negativa. }\end{array}$ & $\begin{array}{c}\text { Adolescentes em escolas particulares e com relatos de } \\
\text { percepção de saúde negativa apresentaram alta } \\
\text { prevalência de comportamento inativo. Na verificação } \\
\text { dos fatores associados, o sexo feminino mostrou } \\
\text { magnitude de associação de 1,84 com o comportamento } \\
\text { inativo. Estar institucionalizado em escola particular } \\
\text { mostrou } 2,54 \text { vezes mais chance de ter comportamento } \\
\text { inativo em comparação aos estudantes das escolas } \\
\text { públicas. }\end{array}$ \\
\hline $\begin{array}{c}\text { Lemes DCM, } \\
\text { et al., } 2018\end{array}$ & $\begin{array}{l}\text { estudar o perfil de bem- } \\
\text { estar entre adolescentes } \\
\text { escolares satisfeitos e } \\
\text { insatisfeitos com a } \\
\text { imagem corporal }\end{array}$ & $\begin{array}{c}1.460 \text { alunos } \\
\text { do nono ano } \\
\text { Canoas/RS } \\
\text { Região sul do } \\
\text { Brasil }\end{array}$ & $\begin{array}{l}\text { Estudo observacional, de base escolar, } \\
\text { analítico e transversal. Os instrumentos } \\
\text { foram: questionário de dados } \\
\text { sociodemográficos; Critério de } \\
\text { Classificação Econômica Brasil; Body } \\
\text { Shape Questionnaire; Escala } \\
\text { Multidimensional Breve de Satisfação } \\
\text { com a Vida em Estudantes; Percepção } \\
\text { de Saúde e de Otimismo e Escala de } \\
\text { Felicidade. Os dados foram analisados } \\
\text { mediante estatística descritiva e análise } \\
\text { discriminante. }\end{array}$ & $\begin{array}{c}\text { Em relação à imagem corporal, } 1.091 \text { ( } 74,7 \%) \text { estavam } \\
\text { satisfeitos. O que mais diferenciou os grupos foi o sexo } \\
(0,680) \text {, a satisfação consigo próprio }(0,644) \text {, a } \\
\text { percepção de saúde }(0,630) \text { e o quanto o adolescente } \\
\text { está feliz com sua saúde }(0,601) \text {. O investimento em uma } \\
\text { abordagem que vincule imagem corporal positiva com } \\
\text { ser saudável em um sentido mais amplo, pode contribuir } \\
\text { com adesão dos adolescentes aos serviços de saúde, } \\
\text { permitindo acessar essa população de uma forma mais } \\
\text { efetiva e menos reguladora. }\end{array}$ \\
\hline $\begin{array}{c}\text { Pedraza DF, } \\
\text { et al., } 2018\end{array}$ & $\begin{array}{l}\text { Avaliar a autopercepção } \\
\text { corporal em escolares } \\
\text { da rede pública de } \\
\text { ensino de Campina } \\
\text { Grande e examinar a } \\
\text { associação com o sexo, } \\
\text { a idade e o estado } \\
\text { nutricional. }\end{array}$ & $\begin{array}{c}1081 \text { crianças } \\
\text { de cinco a dez } \\
\text { anos. } \\
\text { Campina } \\
\text { grande/Paraíba } \\
\text { Região } \\
\text { Nordeste do } \\
\text { brasil }\end{array}$ & $\begin{array}{c}\text { Estudo transversal. Para o estado } \\
\text { nutricional foi obtido por meio do IMC/I. } \\
\text { Para a avaliação da percepção corporal } \\
\text { utilizou-se a escala Children's Body } \\
\text { Image Scale. } \\
\text { Os calculos foram realizados com a } \\
\text { utilizacao do programa WHO } \\
\text { AnthroPlus } 2009 \text {. }\end{array}$ & $\begin{array}{l}\text { A prevalência de sobrepeso foi de } 75,9 \% \text {. Crianças com } \\
\text { sobrepeso e obesas apresentaram maiores percentuais } \\
\text { de insatisfação corporal. Das crianças obesas, } 73,7 \% \\
\text { perceberam-se mais magras. Constatou-se que } 94,7 \% \\
\text { dos escolares com sobrepeso, } 98 \% \text { dos obesos e } 41,8 \% \\
\text { dos eutróficos gostariam de ser mais magros, enquanto } \\
83,3 \% \text { dos desnutridos desejariam ser mais gordos. A } \\
\text { visão mais distorcida do corpo verificou-se nas crianças } \\
\text { mais velhas e nos meninos. Aponta-se que o sexo, a } \\
\text { idade e o estado nutricional podem influenciar a } \\
\text { percepção corporal. }\end{array}$ \\
\hline
\end{tabular}

REAS/EJCH | Vol.12(3) | e2505 | DOI: https://doi.org/10.25248/reas.e2505.2020 Página 6 de 9 
O estudo de Farias E, et al., (2019), fala sobre o comportamento negativo em relação aos cuidados com a saúde como sendo um problema mundial, haja vista que crianças e adolescentes estão ficando cada mais inativos em relação à prática de atividades física e também se alimentando de produtos industrializados com maior frequência. Os autores ainda referenciaram que entre os anos de 2009 e 2015 (Relatório do Instituto brasileiro de Geografia e Estatística - IBGE), mostraram uma diminuição na quantidade de tempo em que esse público tem se exercitado por semana.

O estudo evidenciou um grau elevado com relação ao comportamento inativo dos adolescentes participantes, sendo mais evidentes entre as participantes do sexo feminino. Com a facilidade de meios de transportes, os alunos têm utilizado o meio de transporte motorizado, além do que outro ponto em destaque no estudo foi sobre a percepção que eles têm de sua saúde, pois os mesmos pontuaram (em sua grande maioria - 49.2\%), terem uma saúde negativa. Os alunos ainda apresentaram um quantitativo elevado de acúmulo de gordura em seu corpo, evidenciando assim os pontos relacionados sobre alimentação inadequada e a mínima, ou mesmo nenhuma, prática de atividade física. Essa questão permeia sobre como o aluno percebe seu corpo, não se sentindo bem e resultando em uma sensação de estar doente. Lembrando que, ao deixar de cuidar do corpo, o indivíduo pode ser acometido por diversas doenças, que poderiam ser evitadas caso optassem em praticar atividade física, cuidar da alimentação, da higiene e assim por diante (BRASIL, 2015).

Nesse estudo ainda foi citado sobre os possíveis fatores que levaram aos resultados encontrados. Os períodos chuvosos, fazendo com que os alunos optem por ir de ônibus ou carro, além do que a cada ano, fica mais fácil o acesso as diversas tecnologias existentes, assim os adolescentes optam em ficar nos videogames, celulares, tabletes e TVs, ao invés de fazer uma caminhada, pedalar ou optar por outra atividade física. Porém, os autores observaram que os fatores podem ser distintos, já que nem todas as regiões brasileiras apresentam os mesmos ciclos de chuvas encontradas na região norte (FARIAS E, et al., 2019), O estudo não citou se houve alguma ação educativa afim de levar conhecimentos aos envolvidos para que pudessem conscientizar-se de sua situação e refletir sobre as práticas com cuidados com seu corpo e saúde, afim de serem adolescentes e adultos mais saudáveis (BRASIL, 2017).

Lemes DCM, et al., (2018), em seu estudo falam sobre as inúmeras transformações que ocorrem no corpo no período da adolescência, podendo acarretar em insatisfação pessoal e por fim, o indivíduo acaba por ter uma imagem distorcida em relação ao seu corpo. Ainda de acordo com os autores, nesta fase os jovens tendem a ter uma preocupação excessiva com sua aparência física, por acharem que nãos se encaixam no padrão social criado ao longo dos anos. O estudo cita que, o corpo é visto de duas maneiras: a primeira se relaciona com as transformações biológicas e sociais e a outra está relacionada a estética aceita em nossos dias, que são propagadas pelos meios televisivos e mídias em geral.

Os autores fizeram uma relação entre a imagem corporal com o bem-estar e a saúde, refletindo sobre os impactos que as percepções de corpo que o indivíduo tem, que podem influenciar diretamente em sua saúde, tanto de forma positiva quanto de forma negativa. Foi destacado ainda que os autores não encontraram nenhum estudo dentro desta temática envolvendo escolares, salientando a importância do estudo apresentado por eles (LEMES DCM, et al., 2018).

Os resultados que foram obtidos mostraram que os adolescentes estavam satisfeitos com seu corpo. Os autores citaram outros estudos realizados com foco na satisfação da imagem corporal entre os adolescentes, que foram realizados em outros locais da Região Sul, onde os adolescentes estão satisfeitos com a imagem corporal. Já em contraposição do que foi encontrado no Sul, na região sudeste eles citaram que os estudos feitos, evidenciam que os adolescentes se encontram insatisfeitos com a imagem corporal. Os autores argumentaram que tal distanciamento de resultados pode ter relação com os instrumentos utilizados. Eles ainda completam que a grande parte dos pesquisados que se encontram insatisfeitos com seu corpo são do sexo feminino. Os autores citaram alguns fatores que podem estar associados à insatisfação. Dentre os fatores estão: as pressões sociais para um peso ideal que tem estreitam ligação com a magreza, o que pode levar à sério prejuízo à saúde, por muitas vezes buscarem a qualquer custo um corpo perfeito, esquecendo dos cuidados que deveriam ter com sua saúde (LEMES DCM, et al., 2018).

A insatisfação com a imagem que os adolescentes têm de seus corpos podem levá-los à uma situação delicada, haja vista que esses sentimentos podem influenciar em sua autoestima, podendo provocar tristezas

REAS/EJCH | Vol.12(3) | e2505 | DOI: https://doi.org/10.25248/reas.e2505.2020 Página 7 de 9 
e aumentando a possibilidade de depressão, que já se tornou um problema de saúde no mundo inteiro (Claumann GS, et al., 2017).

Neste estudo, os autores trouxeram a relação que se faz entre a imagem corporal com os cuidados com a saúde, pois saúde vai além da ausência de enfermidade. Em seus achados, os autores notaram que os adolescentes são um público vulnerável quanto ás questões de saúde, pois nessa fase há diversas transformações em seu corpo, além das interações sociais que lhes impõe um estereótipo corporal dito como certo, fazendo com estes jovens sofram pressões constantes e levando à questionamentos internos afetando diretamente sua saúde física e mental (LEMES DCM, et al., 2018). Fica claro, em mais esse estudo o fato de que ações educativas no espaço escolar, que possam ensinar os alunos a cuidarem da saúde, seja um dos caminhos à serem percorrido na busca de uma conscientização para que estes jovens se auto percebam enquanto agente transformadores de suas interações para uma saúde melhor (BRASIL, 2009).

Pedraza DF, et al. (2018), apontaram que a maioria dos participantes se encontram acima do peso ou obesos, causados por má alimentação, inatividade física e em outros casos, por fatores biológicos. Sobre esse ponto, a Organização Mundial da Saúde (OMS), mostra que a obesidade infantil é um problema que deve ser tratado pois já é considerado um problema de saúde pública e tem crescido drasticamente em crianças na faixa etária escolar (OMS, 2017). Nesse estudo, podemos notar a presença de atividades voltadas para o cuidado com o corpo e a saúde, destacando assim sobre a importância do desenvolvimento de ações educativas que possam priorizar a prevenção, orientando os alunos para que possam cuidar de sua saúde a partir do momento em que as formas corretas deste cuidado e por fim optem por hábitos saudáveis (BRASIL, 2009).

O estudo ainda relata sobre a imagem que os escolares têm de si, gerando uma montanha de problemas, gerando uma imagem corporal distorcida, o que pode acarretar em problemas como comportamentos inadequados para sua alimentação, comorbidades psíquicas, além dos transtornos, medos, variação do estado de alegria/tristeza e danos à parte biológica (PEDRAZA DF, et al.,2018). O estudo ainda citou que a insatisfação com o corpo está ficando cada vez mais precoce, o que nos faz refletir sobre quais fatores estão levando essas crianças a se preocuparem com a parte estética em um momento que deveriam se preocupar com o brincar, diversão e interação com outras crianças de sua idade. Um dos pontos, pode ser relacionado com as mídias que tem propagado sobre as modas também no universo infantil, provocando uma onda de insatisfação com a própria imagem também entre as crianças (PEDRAZA DF, et al.,2018).

\section{CONSIDERAÇÕES FINAIS}

Podemos observar nos estudos, o quanto as crianças e os adolescentes não têm cuidado do seu corpo e sua saúde de forma satisfatória, pois que notamos nos estudos foram hábitos alimentares errados, em que preferem doces, refrigerantes, além de apresentar uma maior porcentagem na inatividade, significando que as mesmas não estão praticando atividade física periodicamente, preferindo os computadores, tablets e celulares (Quadro 1). Outra questão é que relacionado sobre a percepção que tem de seus corpos, a maioria dos participantes tem uma visão diferente daquilo que realmente são, e eles também, em suas respostas diziam querer ter um corpo diferente. Salientamos então sobre a importância de refletir sobre a possibilidade de inserir no meio escolar, ações educativas no trato com os cuidados com o corpo, afim de que as crianças e os jovens possam se conhecer e por fim, cuidar de si para que tenham uma vida mais saudável e a perspectiva de uma vida adulta melhor.

\section{REFERÊNCIAS}

1. BARDIN L. Análise de Conteúdo. Lisboa - Portugal, Edições 70, 2011; 280p.

2. BRASIL. Parâmetro Curriculares Nacionais (PCNs). Educação Física. Ensino Fundamental. Terceiro e Quarto Ciclos. Brasília: MEC/SEF, 1998; 96p.

3. BRASIL. Lei de Diretrizes e Bases da Educação Nacional. Lei número 9394, 20 de dezembro de 2017; 63p.

4. BRASIL. Brasília. Ministério da Saúde. Atividade Física. 2017. Disponível em: <http://www.saude.gov.br/component/content/article/781-atividades-fisicas/40390-atividade-fisica>. Acesso em: 19 dez. 2019

5. BRASIL. Base Nacional Comum Curricular. Brasília: MEC, 2018. Disponível em: http://basenacionalcomum.mec.gov.br/images/BNC C_20dez_site.pdf. Acesso em: 03 de nov. 2019.

REAS/EJCH | Vol.12(3) | e2505 | DOI: https://doi.org/10.25248/reas.e2505.2020 Página 8 de 9 
6. BRASIL. Ministério da Saúde. Adolescência Saudável. 2015. Biblioteca Virtual em Saúde. Disponível em: <http://bvsms.saude.gov.br/dicas-em-saude/411-adolescencia-saudavel>. Acesso em: 23 nov. 2019.

7. BRASIL. Ministério da Saúde. Secretaria de Atenção à Saúde. Departamento de Ações Programáticas e Estratégicas. Proteger e cuidar da saúde de adolescentes na atenção básica [recurso eletrônico] / Ministério da Saúde, Secretaria de Atenção à Saúde, Departamento de Ações Programáticas e Estratégicas. - Brasília: Ministério da Saúde, 2017234p.

8. BRASIL. Ministério da Saúde. Secretaria de Atenção à Saúde. Departamento de Atenção Básica. Saúde na escola / Ministério da Saúde, Secretaria de Atenção à Saúde, Departamento de Atenção Básica. - Brasília: Ministério da Saúde, 2009; 96p

9. CLAUMANN GS, et al. Associação entre insatisfação com a imagem corporal e aptidão física relacionada à saúde em adolescentes. Ciência \& Saúde Coletiva, 2019; 24(4): 1299-1308.

10. DA SILVA MC, BAPTISTA GG. O corpo na/da Escola: As possibilidades da Educação Física Escolar na (Des) Construção das Representações corporais. Revista Contemporânea de Educação, 2014; 9(18): 338-356.

11. FARIAS E, et al. INACTIVE BEHAVIOR IN ADOLESCENT STUDENTS OF THE BRAZILIAN WESTERN AMAZON. Revista Paulista de Pediatria, 2019; 37(3): 345-350.

12. FICAGNA, JB. Imagem Corporal E Adolescência No Contexto Da Educação Física Escolar. Trabalho de Conclusão de Curso (Curso de Graduação em Educação Física) - Departamento de Humanidades e Educação, Universidade Regional do Noroeste do Estado do Rio Grande do Sul, ljuí - RS. 2014; 42 p.

13. FONSECA E, et al. Hygiene care - bath: meanings and perspectives of nurses. Revista de Enfermagem Referência, 2015; 5: 37-45.

14. KRAEMER FB, et al. O discurso sobre a alimentação saudável como estratégia de biopoder. Physis: Revista de Saúde Coletiva, 2014; 24(4): 1337-1360.

15. LEMES DCM, et al. Satisfação com a imagem corporal e bem-estar subjetivo entre adolescentes escolares do ensino fundamental da rede pública estadual de Canoas/RS, Brasil. Ciência \& Saúde Coletiva, 2018; 23(12): 4289-4298.

16. LIMA ACD, et al. Alterações Sensoriais Em Respiradores Orais: Revisão Sistemática Baseada No Método Prisma. Rev. Paul Pediatr, 2018; 1-7.

17. MOHER D, et al. Preferred reporting items for systematic review and meta-analysis protocols (PRISMA-P) 2015 statement. Systematic Reviews, [s.I.], v. 4, n. 1, p.335-342, 1 jan. 2015. Springer Science and Business Media LLC. http://dx.doi.org/10.1186/2046-4053-4-1.

18. OLIVEIRA FPSL, et al. Percepção de escolares do ensino fundamental sobre o Programa Saúde na Escola: um estudo de caso em Belo Horizonte, Brasil. Ciência \& Saúde Coletiva, [s.I.], v. 23, n. 9, p.2891-2898, set. 2018. FapUNIFESP (SciELO). http://dx.doi.org/10.1590/1413-81232018239.16582018.

19. OLIVEIRA JPS. A Constituição Dos Saberes Escolares Em Saúde Na Educação Física Escolar: Uma Análise Sobre A Prática Pedagógica De Professores Da Rede Pública Estadual De Pernambuco.' Dissertação (Mestrado Em Educação Física) - Universidade De Pernambuco, Recife, 2017; 90p.

20. Organização Mundial da Saúde (Org.). Obesidade entre crianças e adolescentes aumentou dez vezes em quatro décadas, revela novo estudo do Imperial College London e da OMS. 2017. Disponível em: <https://www.paho.org/bra/index.php?option=com_content\&view=article\&id=5527:obesidade-entre-criancas-eadolescentes-aumentou-dez-vezes-em-quatro-decadas-revela-novo-estudo-do-imperial-college-london-e-daoms\&ltemid $=820>$. Acesso em: 20 nov. 2019.

21. PEDRAZA DF, et al. Prevalência e fatores associados a autopercepção corporal em escolares do nordeste brasileiro. Rev. Eletr. Enf., 2018; 20(2): 1-20

22. SILVA A, et al. A EDUCAÇÃO FÍSICA NO ENSINO MÉDIO: UM OLHAR SOBRE O CORPO. Movimento, 2015; 21(3): 673-685.

23. THE PRISMA GROUP (Org.). Principais itens para relatar Revisões sistemáticas e Meta-análises: A recomendação PRISMA. Epidemiologia e Serviços de Saúde, 2015; 24(2): 335-342.

24. ZACARIAS EFJ, HIGUCHI MIG. Relação pessoa-ambiente: caminhos para uma vida sustentável. Interações (campo Grande), 2017; 18(3): 121-129. 